\title{
UPAYA KEPALA SEKOLAH DALAM MENINGKATKAN MOTIVASI KERJA GURU DI SDIT TAQIYYA ROSYIDA KARTASURA SUKOHARJO TAHUN AJARAN 2019/2020
}

\author{
Nur Istiqomah \\ SDIT MTA Surakarta \\ E-mail: isti28nur@gmail.com
}

\begin{abstract}
The purpose of this study was to determine the principal's efforts in increasing the work motivation of teachers at SDIT Taqiyya Rosyida Kartasura Sukoharjo. This research is a qualitative descriptive study which was carried out from November 2019 to May 2020. The subject of this study was the Principal of SDIT Taqiyya Rosyida Kartasura. Data collection techniques are carried out through interviews, observation and documentation. Test the validity of the data through triangulation of sources, methods and theories. While the data analysis technique uses an interactive analysis model which includes: data collection, data reduction, data presentation and conclusion. The results of this study indicate that the principal's efforts in increasing teacher work motivation are through setting the physical environment, setting the work atmosphere, providing motivation, discipline, giving awards, increasing the development of learning resource centers, training or training teachers regularly and picnics for teachers.
\end{abstract}

Keywords: Principal's Efforts; Teacher's Work Motivation

Abstrak Tujuan penelitian ini adalah untuk mengetahui upaya kepala sekolah dalam meningkatkan motivasi kerja guru di SDIT Taqiyya Rosyida Kartasura Sukoharjo. Penelitian ini merupakan penelitian deskriptif kualitatif yang dilaksanakkan pada bulan November 2019 hingga Mei 2020. Subjek dalam penelitian ini adalah Kepala Sekolah SDIT Taqiyya Rosyida Kartasura. Teknik pengumpulan data dilakukan melalui wawancara, observasi dan dokumentasi. Uji validitas data melalui triangulasi sumber, metode dan teori. Sedangkan teknik analisis datanya menggunakan model analisis interaktif yang meliputi: pengumpulan data, reduksi data, penyajian data dan penarikan kesimpulan. Hasil penelitian ini menunjukkan bahwa upaya kepala sekolah dalam meningkatkan motivasi kerja guru adalah melalui pengaturan lingkungan fisik, pengaturan suasana kerja, pemberian motivasi, pendisiplinan, pemberian penghargaan, peningkatan pengembangan pusat sumber belajar, pelatihan atau pelatihan guru secara berkala dan piknik untuk guru.

Kata Kunci: Motivasi Kerja Guru; Upaya Kepala Sekolah

\section{PENDAHULUAN}

Sekolah merupakan tempat yang dirancang untuk kegiatan proses pembelajaran dimana orang yang berada didalamnya memiliki peran untuk mengatur keberlangsungan jalannya kegiatan belajar mengajar. Semua pihak yang terlibat di lingkungan sekolah seperti kepala sekolah, guru-guru, karyawan dan staf memiliki tanggung jawab berupa tugas-tugas pendidikan yang telah dibebankan kepadanya. Nurhayati (2014) menyatakan keberadaan pemimpin efektif akan dapat memotivasi stafnya untuk berprestasi dan bekerja dengan semangat tinggi. Motivasi 
yang tinggi akan melahirkan kualitas layanan pendidikan yang lebih baik sehingga dapat menghasilkan siswa yang berprestasi. Oleh karena itu salah satu indikator keberhasilan prestasi belajar siswa juga tergantung dari kinerja guru.

Dalam Undang-undang no 14 tahun 2005 menerangkan bahwa kinerja guru dapat dilihat dan diukur berdasarkan kriteria kompetensi guru yaitu dari segi kompetensi pedagogik, kepribadian, sosial, dan professional (Depdiknas, 2005). Kompetensi guru tersebut dapat dipantau dan ditingkatkan tergantung berdasarkan kemampuan kepala sekolah dalam usaha pengelolaan dan pembinaan sekolah. Kepala sekolah memiliki peranan penting dalam pengaruh kemajuan sekolah, oleh karena itu seorang pemimpin yang baik adalah pemimpin yang dapat memotivasi dirinya sendiri dan memotivasi para pengikutnya.

Motivasi sangat dibutuhkan karena akan mempengaruhi kinerja para guru. Motivasi kerja guru merupakan kerja keras dari kepala sekolah yang turut mengupayakan banyak hal agar motivasi tersebut senantiasa ada di dalam benak guru. Oleh karena itu agar guru dapat mengajar dengan bahagia, diperlukan peran kepala sekolah untuk meningkatkan motivasi kerjanya. Peningkatan tersebut dapat diwujudkan dengan memberikan pelayanan yang baik berupa pengaturan lingkungan kerja yang nyaman, dorongan yang kuat berupa bimbingan dan pemberian penghargaan serta upah yang sepadan. Harapannya adalah jika motivasi kerja guru meningkat, maka kinerjanya juga akan meningkat demikian juga dengan mutu pembelajarannya, sehingga diharapkan prestasi belajar anak akan meningkat.

Menurut penelitian Muhyadi \& Pramesti (2018) supervisi kepala sekolah, motivasi kerja, dan iklim kerja, dan status social secara bersama-sama berpengaruh signifikan terhadap kinerja guru. Motivasi kerja guru termasuk salah satu aspek yang berpengaruh dalam kinerja guru, semakin tinggi motivasi kerja dalam mendidik guru, maka semakin tinggi pula kinerja yang dihasilkan guru (Abdulsalam \& Mawoli, 2012; Andari, 2013; Muhyadi \& Pramesti, 2018) Kenyataannya motivasi kerja seorang guru dapat naik turun bahkan hilang sehingga pelaksanaan tugas dari para guru terkadang tidak sesuai dengan apa yang diharapkan. Hal ini terlihat dari beberapa tanda: (1) Rendahnya pemahaman tentang strategi pembelajaran; (2) Kurangnya kemahiran dalam mengelola kelas; (3) Rendahnya kemampuan melakukan dan memanfatkan penelitian tindakan kelas (Classroom Action Research); (4) Kurangnya kedisiplinan; (5) Rendahnya komitmen profesi; (6) Rendahnya kemampuan manajemen waktu (Simarmata, 2014: 656). 
Hal ini menjadi tantangan bagi kepala sekolah untuk terus berupaya meningkatkan motivasi kerja guru agar para guru dapat menyelesaikan serangkaian tugas dengan baik dan mampu menyiapkan apa saja yang menjadi kebutuhan peserta didik supaya keberlangsungan proses belajar mengajar dapat berjalan secara optimal, sehingga kepala sekolah dalam menjalankan perannya sebagai motivator harus senantiasa memberikan dorongan dan semangat kepada guru agar dapat memaksimalkan kinerjanya. Jika guru dapat memberikan kinerja yang bagus maka hal ini akan berpengaruh pada prestasi yang akan di capai peserta didik dan sekolah.

Sejalan dengan penelitian (Tukiyo, 2015: 165) menyatakan bahwa berdasarkan hasil penelitian yang telah dilakukannya sebagian besar guru yaitu sebanyak 42 orang atau sebesar 65,625\% memiliki motivasi kerja dalam kategori sedang. Hal ini perlu diupayakan oleh para kepala sekolah agar para guru memiliki motivasi kerja yang tinggi, sebab motivasi kerja guru akan berpengaruh terhadap kinerja guru yang bersangkutan. Implikasi dari hasil penelitian tersebut adalah bahwa para kepala sekolah perlu menempuh upaya-upaya yang dapat meningkatkan motivasi dan kepuasan kerja guru. Jika motivasi dan kepuasan kerja guru tinggi maka diharapkan kinerja guru di sekolah yang bersangkutan juga tinggi. Berdasarkan latar belakang masalah diatas dan atas tinjauan pentingnya motivasi kerja guru maka penulis tertarik untuk mengkaji lebih dalam mengenai “Upaya Kepala Sekolah dalam Meningkatkan Motivasi Kerja Guru di SDIT Taqiyya Rosyida Kartasura Sukoharjo Tahun Ajaran 2019/2020".

\section{METODE PENELITIAN}

Penelitian ini menggunakan jenis penelitian deskriptif kualitatif yang dilaksanakan di SDIT Taqiyya Rosyida Kartasura Sukoharjo pada bulan November 2019 sampai bulan April tahun 2020. Penelitian kualitatif dilakukan untuk memberikan pemahaman mengenai fenomena tertentu contohnya seperti perilaku, persepsi, motivasi, tindakan dan lainnya secara menyeluruh dengan cara penggambaran dalam bentuk kata-kata dan bahasa (Moleong, 2017: 6). Subjek penelitian ini adalah pihak yang terlibat dalam penelitian atau pihak yang menjadi sasaran untuk diteliti. Adapun yang menjadi subjek dalam penelitian ini adalah kepala sekolah, sedangkan Informan dalam penelitian ini adalah wali kelas 2A, wali kelas 6B dan waka kesiswaan di SDIT Taqiyya Rosyida Kartasura.

Teknik Pengumpulan data pada penelitian ini meliputi observasi, wawancara dan dokumentasi. Wawancara yang dilakukan secara langsung disekolah. Adapun teknik pemeriksaan keabsahan data yang di gunakan adalah triangulasi, triangulasi bertujuan untuk 
memeriksa keabsahan data dengan cara membandingkan berbagai data yang telah diperoleh peneliti (Moleong, 2016: 330). Adapun dalam penyajian keabsahan data menggunakan triangulasi sumber, triangulasi teknik dan triangulasi teori.

\section{HASIL DAN PEMBAHASAN}

SDIT Taqiyya Rosyida Kartasura Sukoharjo merupakan lembaga pendidikan di bawah pimpinan yayasan Taqiyya Rosyida. Sekolah dasar ini merupakan salah satu sekolah berbasis IT (Islam Terpadu) yang berada di daerah tersebut. Proses pembangunan sekolah ini selalu mengalami peningkatan dalam berbagai segi terlihat dari semakin banyaknya jumlah siswa, semakin lengkapnya sarana dan prasarana dan semakin banyak gedung yang dibangun.

Kepala sekolah selalu berusaha meningkatkan kualitas pendidikan sekolah yang dipimpinnya, setiap tahun mengalami kemajuan yang pesat, bisa dilihat dari sarana dan prasarana yang semakin banyak dan pembangunan penambahan gedung sekolah. Beliau merupakan kepala sekolah yang inovatif terbukti dari nuansa alam yang diciptakan di lingkungan sekolah ini terasa nyaman dan sejuk, pembangunan gazebo, taman-taman yang asri, rumah hidroponik dan adanya kolam renang menjadi daya tarik tersendiri bagi masyarakat. Hingga saat ini, SDIT Taqiyya Rosyida mengalami banyak kemajuan di setiap tahunnya, mulai dari jumlah siswa yang semakin banyak dan semakin banyak pula gedung yang dibangun. Sehingga pada tanggal 16 Oktober 2018 SDIT Taqiyya Rosyida telah memperoleh Akreditasi A.

Salah satu tugas dan peran kepala sekolah adalah sebagai motivator, motivator disini bisa diartikan bahwa kepala sekolah menjadi pendorong dan penggerak bagi bawahannya yakin tenaga pendidik dan tenaga kependidikan dalam memenuhi tugas sekolah. Tugas-tugas yang ada harus dapat diselesaikan dengan tepat waktu dan semaksimal mungkin agar dapat mencapai keberhasilan suatu sekolah seperti visi misi sekolah yang telah di sepakati bersama.

Berdasarkan observasi peneliti, upaya kepala sekolah sebagai motivator di SDIT Taqiyya Rosyida Kartasura berdasarkan wawancara penulis dengan kepala sekolah, yaitu: Pertama, Kepala sekolah menumbuhkan motivasi kerja guru dengan memperbaiki pengaturan lingkungan fisik sekolah. SDIT Taqiyya Rosyida merupakan sekolah dasar yang memiliki pengaturan lingkungan fisik yang nyaman dan asri, disetiap luar ruang kelas terdapat tanamantanaman hijau yang membuat setiap mata yang memandang menjadi fresh. Banyak sekali berbagai pepohonan, hiasan dinding dan kolam ikan yang berada di halaman sekolah. Di setiap 
ruang kelaspun terdapat tempat untuk cuci tangan anak-anak sehingga lebih mudah dalam menjaga kebersihan.

SDIT Taqiyya Rosyida Kartasura memberikan pelayanan terbaik dari segi pengaturan lingkungan fisik, karena suasana yang nyaman akan menimbulkan motivasi belajar baik guru dan siswa. Pengaturan lingkungan fisik SDIT Taqiyya Rosyida Kartasura memiliki konsep sekolah yang memiliki banyak taman. Berdasarkan hasil wawancara peneliti degan kepala sekolah, untuk menciptakan lingkungan fisik yang nyaman, diadakannya taman yang sejuk dan akan membuat mata sejuk dan otak menjadi fresh. Pengadaan gazebo sebagai penanda daya beda untuk pembelajaran dan menerima tamu dan sebagai wadah belajar anak dalam pembelajaran AQT (Al-Quran dan Tahfidz). Adanya kolam renang sebagai sarana sport center setiap pekan ada kegiatan renang untuk para siswa bergantian antara kelas satu sampai kelas enam.

Kedua, menumbuhkan suasana kerja yang baik dan harmonis. Kepala sekolah melakukan pendekatan terhadap guru yaitu dengan menumbuhkan rasa kebersamaan, kekompakaan, dan kerja sama yang baik terhadap guru dengan rasa kekeluargaan. Kepala sekolah dan guru juga menanamkan pembiasan adab 3S (Senyum, Salam, Sapa). Berdaarkan observasi, Kepala Sekolah SDIT Taqiyya Rosyida Kartasura memiliki sikap ramah tamah dan loyal kepada siapa saja termasuk kepada guru sehingga di lingkungan sekolah para guru tidak sungkan untuk menyapa kepala sekolah begitu juga sebaliknya. Kepala sekolah tidak sungkan berbincangbincang santai dengan para guru yang ditemuinya, sudah seperti keluarga atau sahabat karib. Hubungan antara siswa dengan guru dan kepala sekolahpun sangat baik, saling menyapa, bersalaman dan saling tersenyum. Apabila bertemu, hal ini juga berlaku kepada para tamu yang datang ke sekolah seperti yang dilakukan kepada peneliti. Selain itu para siswa di SDIT Taqiyya Rosyida ditanamkan budaya adab sejak dini, seperti adab masuk kelas, adab bila berjalan di depan orang yang dewasa ataupun orang yang sedang duduk, para siswa tersenyum dan membungkukkan badan.

Pelayanan di sekolah ini memiliki prinsip $5 \mathrm{H}, 5$ prinsip dalam pelayanan membangun suasana kerja, yang pertama yaitu happines (semua harus senang), help (tolong menolong), hope (memiliki harapan), healthy (sehat) bagaimana mendidik anak kuat jika tidak sehat, humor (adanya humor agar suasana menjadi cair).

Ketiga, menanamkan kedisiplinan. Kedisiplinan disini tidak hanya berlaku untuk guru, tetapi juga kepada kepala sekolah sendiri. Kepala sekolah harus menjadi teladan untuk para 
guru. Pemberian teladan yang baik dapat memberikan contoh berdisiplin yang baik kepada bawahan sehingga dapat memotivasi bawahannya dalam melakukan suatu pekerjaan. Kepala sekolah sebagai figur sentral harus menyadari bahwa terbentuknya suatu kebiasaan dan sikap dalam konteks disiplin sekolah dipengaruhi oleh pribadi dan gaya kepemimpinan kepala sekolah yang visioner. Contoh disiplin yakni disiplin datang ke sekolah dan disiplin dalam menyelesaikan tugas dengan adanya kedisiplinan diharapkan dapat meningkatkan produktivitas sekolah dan mutu pendidikan.

Kedisiplinan menjadi hal yang ditekankan oleh kepala sekolah, adanya rewards untuk guru yang mendapatkan gelar guru terdisiplin dapat memacu guru-guru yang lain untuk melakukan hal yang sama Dalam hal kedatangan guru di sekolah sudah menggunakan fingerprint untuk mengukur kedatangan dan kepulangan guru. Dalam hal administrasi guru, ada koordinator administratif biasanya akan ada pengecekan dari divisi kurikulum bagian administrasi, penanggungjawab administrasi laporan ke kurikulum lalu kurikulum baru ke kepala sekolah yang dilaporkan setiap hari selasa, untuk absensi, daftar nilai dan jurnal mengajar dikoreksi di awal bulan.

Keempat, memberikan dorongan. Kepala sekolah SDIT Taqiyya Rosyida adalah kepala sekolah yang visioner, inovatif dan selalu memberikan motivasi atau dorongan kepada bawahannya (tenaga pendidik dan kependidikan). Berdasarkan penelitian Iskandar (2013) dan Setiyati (2014) terdapat pengaruh postitif antara kepemimpinan kepala sekolah, dan motivasi keja terhadap kinerja guru. Motivasi merupakan bagian penting bagi seorang guru, tanpa motivasi guru bisa saja tidak memiliki semangat dalam mengajar, hal ini dapat mempengaruhi kualitas belajar siswa dikelas. Oleh karena itu, kepala sekolah hendaknya memperhatikan apa yang sedang terjadi dan apa yang dibutuhkan oleh seorang guru, agar semua proses pembelajaran dapat berjalan sesuai dengan apa yang telah direncanakan, hal ini juga sejalan dengan penelitian Simarmata (2020) motivasi sangat diperlukan untuk mendapaatkan produktivitas kerja yang tinggi. Motivasi kerja guru dapat dilakukan melalui kerendahan hati, keteladanan, disiplin dan kelembutan yang dimiliki seorang pemimpin (Wardani, 2016).

Kelima, pemberian penghargaan atau rewards. Kepala sekolah memberikan hadiah baik secara perseorangan ataupun kelompok yang memiliki prestasi kerja yang baik. Penghargaan dapat berupa hadiah, uang ataupun sertifikat. Seperti yang dilakukan oleh Bapak Kepala Sekolah memberikan hadiah pada bulan juli 2019 kepada guru yang memiliki keunggulan yakni guru 
terdisiplin, terkreatif, berprestasi, tertib administrasi, terfavorit, dan terupdate. Pemberian penghargaan untuk guru kemarin dilakukan sekitar bulan juli 2019 dan bulan januari 2020, dengan kategori guru terdisiplin, terkreatif, berprestasi, tertib administrasi, terfavorite, terupdate pemberian penghargaan ini dilaksanakan kemarin sekitar bulan juli.

Keenam, Menyediakan Pengembangan Pusat Sumber Belajar. Pengembangan pusat sumber belajar dengan kata lain menyediakan sarana dan prasarana yang memadai. Kepala sekolah berusaha menyediakan kebutuhan guru dalam menunjang proses belajar mengajar yang efektif. Seperti menyediakan sumber belajar, media dan alat pembelajaran. Saat ini SDIT Taqiyya Rosyida Kartasura dari tahun ketahun mengalami peningkatan dalam hal sarana dan prasarana, salah satunya yaitu adanya ruangan yang disebut dengan bioskop edukasi digunakan dalam kegiatan IPA, yakni bagian pembelajaran diluar kurikulum, jika anak-anak sedang istirahat bisa melihat video pembelajaran, ada juga perpustakaan digital yang memiliki 14 komputer disitu ada sistem perpustakaan yang bisa untuk membuka $e$ - book atau video-video islami, sarana pembelajaran lain yakni adanya pojok baca di setiap ruang kelas, adanya LCD sebagai pendukung pembelajaran di kelas.

Berdasarkan observasi, Keadaan sarana dan prasarana yang sudah memadai seperti adanya kelengkapan yang memudahkan proses pembelajaran seperti LCD Proyektor, komputer, laptop, pengeras suara di setiap kelas, bioskop edukasi, kolam renang, aula dan halaman sekolah yang luas dapat memudahkan para siswa dan guru dalam melaksanakan kegiatan pembelajaran. Hal ini menujukkan bahwa SDIT Taqiyya Rosyida Kartasura selalu berusaha untuk meningkatkan penyediaan pengembangan pusat sumber belajar yang memadai demi terciptanya pembelajaran yang efektif.

Ketujuh, adanya pelatihan dan pembinaan guru. Kepala sekolah telah memprogramkan adanya pelatihan dan pembinaan guru Pembinaan dan pelatihan guru dilaksanakan baik di dalam lingkungan sekolah maupun di luar sekolah. Pembinaan yang diadakan di dalam lingkungan sekolah dilaksanakan secara rutin di setiap pekan khusus untuk para guru di SDIT Taqiyya Rosyida Kartasura. Hal ini dilakukan untuk memberikan wawasan dan pemahaman yang lebih luas kepada guru. Selain itu untuk mencari solusi atas suatu permasalahan yang sedang terjadi di dalam dunia pendidikan. Kegiatan ini akan dapat meningkatkan kedisiplinan kerja guru sejalan dengan penelitian Rusmawati (2013).

SDIT Taqiyya Rosyida memiliki agenda rutin dalam pembinaan guru, para guru 
diberikan pembinaan dan bimbingan yang diadakan setiap satu pekan sekali, materinya sudah terbukukan sesuai dengan risalah guru ataupun materi-materi yang sedang populer. Contoh pelatihan yang pernah di agendakan oleh kepala sekolah SDIT Taqiyya Rosyida untuk guru dan karyawan adalah sebagai berikut:

Tabel 1.2 Pelatihan dan pembinaan guru

\begin{tabular}{|c|c|c|}
\hline No. & Tanggal & Tema \\
\hline 1 & $\begin{array}{l}\text { Kamis, } \\
4 \text { April } 2020\end{array}$ & $\begin{array}{l}\text { Kunjungan ke SDIT Az Zahra Sragen dengan tem } \\
\text { Sharing Pembelajaran AQT }\end{array}$ \\
\hline 2 & $\begin{array}{l}\text { Sabtu, } \\
13 \text { April } 2019\end{array}$ & $\begin{array}{l}\text { Kunci sukses keluarga, anak hebat, dan orang tu } \\
\text { hebat" bersama ust. Cahyadi Takariawan. }\end{array}$ \\
\hline 3 & $\begin{array}{l}\text { Selasa, } \\
2 \text { Juli } 2019\end{array}$ & $\begin{array}{l}\text { Training service excellent untuk pegawai TU, pegawai } \\
\text { satpam, dan pegawai kebersihan oleh Us Arif } \\
\text { Priyanto, S.Pd.I. }\end{array}$ \\
\hline 4 & $\begin{array}{l}\text { Rabu, } \\
\text { 3 Juli } 2019\end{array}$ & Pelatihan dan Upgrade tentang pembelajaran WA \\
\hline 5 & $\begin{array}{l}\text { Rabu, } \\
\text { 3 Juli } 2019\end{array}$ & $\begin{array}{l}\text { Menjadi guru yang beradab untuk membangun generasi } \\
\text { bermartabat. }\end{array}$ \\
\hline 6 & $\begin{array}{l}\text { Sabtu, } \\
24 \text { Agustus } 2019\end{array}$ & Adab Sebelum Ilmu oleh ustadzah Farida \\
\hline 7 & $\begin{array}{l}\text { Selasa, } \\
3 \text { Desember } 2019\end{array}$ & $\begin{array}{l}\text { Menjadi Guru yang dirindukan oleh Dr. Muhamm Munadi, } \\
\text { M.Pd }\end{array}$ \\
\hline 8 & $\begin{array}{l}\text { Rabu, } \\
11 \text { Desember } 201\end{array}$ & $\begin{array}{l}\text { Meningkatkan kualitas guru dalam mempercepat } \\
\text { transformasi pendidikan menuju era society } 5.0 \text { o Dr Cand } \\
\text { Zulfikar Alimuddin. }\end{array}$ \\
\hline 9 & $\begin{array}{l}\text { Jumat, } \\
27 \text { Desember } 201\end{array}$ & $\begin{array}{l}\text { Tingkatkan solidaritas menuju kinerja berkualita oleh } \\
\text { Ustadz Sriyadi selaku ketua dewan pembina yayasan } \\
\text { Taqiyya Rosyida }\end{array}$ \\
\hline 10 & $\begin{array}{l}\text { Sabtu, } \\
28 \text { Desember } 201\end{array}$ & $\begin{array}{l}\text { Menjadi guru konselor di era } 4.0 \text { oleh Ahmad S. } \\
\text { Ahid. S.Psi., S.Pd.I., M.Psi. }\end{array}$ \\
\hline 11 & Desember 2019 & $\begin{array}{l}\text { Bedah kisi-kisi \& Pemantaban USBN bersama guru-guru } \\
\text { kelas VI se-kartausra yang diwakili ole } \\
\text { ustadz lutfi dan ustadzah uul. }\end{array}$ \\
\hline 12 & $\begin{array}{l}\text { Senin, } \\
3 \text { Februari } 2020\end{array}$ & $\begin{array}{l}\text { Mengatasi kesulitan belajar pada siswa SD bersa Budhy } \\
\text { Lestari, S. Psi. }\end{array}$ \\
\hline 13 & $\begin{array}{l}\text { Sabtu, } \\
29 \text { Februari } 2020\end{array}$ & $\begin{array}{l}\text { Sharing bersama Ustadz Mahmud Ismail } \\
\text { (Penulis buku belajar Al-Quran dengan metode Al } \\
\text { Mauzu) }\end{array}$ \\
\hline 14 & $\begin{array}{l}\text { Senin, } \\
2 \text { Maret } 2020\end{array}$ & $\begin{array}{l}\text { Pembinaan dan evaluasi bulanan ustadz/ustadza SDIT } \\
\text { Taqiyya Rosyida oleh ustadz Muslim } \\
\text { selaku koordinator bidang pendidikan Yayasan Taqiyya } \\
\text { Rosyida. }\end{array}$ \\
\hline
\end{tabular}




$\begin{array}{rlr}15 & \begin{array}{l}\text { Sabtu, } \\ \text { 14 Maret 2020 }\end{array} & \text { Lomba membuat media pembelajaran. } \\ 16 & \begin{array}{l}\text { Selasa, } \\ \text { 17 Maret 2020 }\end{array} & \text { Menjadi guru yang profesional oleh ust Sriyadi } \\ \text { Rabu, } & \text { Menjadi guru yang teristimewa oleh ustadz Taufiq } \\ & \text { 18 Maret 2020 }\end{array}$.

(Dokumen SDIT Taqiyya Rosyida yang dikutip pada tanggal 26 April 2020)

Kedelapan. Mengadakan piknik atau rihlah. Piknik untuk para guru di SDIT Taqiyya Rosyida. Hal ini dilakukan selain untuk merekatkan tali silaturahim antar guru juga dapat meningkatkan kesejahteraan psikis guru agar bahagia, jika guru bahagia pasti akan mengajar dengan bahagia juga. Rihlah yang pernah diagendakan untuk para guru SDIT Taqiyya Rosyida di Jatim Park 2, pada tanggal 26-28 April 2019 dengan tema Manajemen Kebahagiaan Ustadz dan Ustadzah SDIT Taqiyya Rosyida Kartasura.

Upaya lain yang dapat meningkatkan motivasi kerja guru yaitu sekolah mengadakan piknik bersama para guru, sebenarnya prinsipnya begini orang kurang bahagia itu bukan karena kurang piknik tetapi kurang ibadah nah piknik ini hanya sebagai bagian penyegaran saja dan manfaat lainnya yaitu dapat menjalin keakraban antar sesama guru. Menurut penelitian Ali, Harun, \& Djailani (2015) dalam meningkatkan motivasi guru dapat dilakukan dengan memberikan perhatian yang penuh dan menjadi pendengar yang baik bagi guru- guru di sekolah terhadap permasalahan yag dihadapai di kelas agar terciptanya lembaga sekolah yang berkualitas.

Kepala Sekolah SDIT Taqiyya Rosyida melakukan berbagai cara untuk dapat meningkatkan mutu pendidikan di sekolahnya. Salah satu usahanya yang gigih, beliau pernah mendapatkan gelar juara yakni memenangkan lomba "Best Practice" atau upaya kepala sekolah dalam memajukan sekolahnya dengan judul "GPS Gerakan Peduli Sekolah untuk meningkatkan fasilitas dan pelayanan sekolah" mendapatkan juara II tingkat karesidenan Solo, Boyolali, Klaten, Sukoharjo, dari 27 SDIT se-korda solo 2. Hal ini dapat menjadi teladan sekaligus inspirasi para guru agar terus belajar dan mengembangkan potensinya sehingga dapat meraih gelar-gelar juara yang lain seperti pemimpinnya.

Secara keseluruhan peran kepala sekolah diatas berperan dalam meningkatkan motivasi kerja guru di SDIT Taqiyya Rosyida. Selain beberapa cara diatas, kemampuan kepala sekolah dalam meningkatkan motivasi kerja guru dapat berupa kemampuan manajerial, dan keterampilan interpersonal terhadap guru (Rahmawati, 2016), karena posisi seorang guru dalam 
pendidikan tidak bisa digantikan oleh alat secanggih apapun, sehingga sebagai top manajemen sekolah penting untuk membangun karakter (Karweti, 2010; Simarmata, 2020).berdasarkan penelitian Hardono (2017) terdapat pengaruh positif kepemiminan kepala sekolah terhadap motivasi kerja guru.

Bersamaan dengan peran kepala sekolah di atas, menurut Fanavi, Mardapi, \& Wuradji (2014) dan Fitrah (2017) kepala sekolah juga harus terus menganalisis hasil belajar siswa terhadap kesesuain visi dan tujuan sekolah dengan cara melaksakan supervise secara rutin kinerja guru. Hasil penelitian Busrin, Aurrahman \& Aswandi (2014) dan Hardono (2017) menunjukkan adanya hubungan antara supervisi dan kemampuan manajerial kepala sekolah terhadap kinerja guru.

\section{KESIMPULAN}

Hasil analisis yang dilakukan tentang upaya kepala sekolah dalam meningkatkan motivasi kerja guru di SDIT Taqiyya Rosyida Kartasura Sukoharjo rahun ajaran 2019/2020 dapat disimpulkan bahwa, Kepala sekolah di SDIT Taqiyya Rosyida Kartasura Sukoharjo dalam meningkatkan motivasi kerja guru menggunakan beberapa cara yaitu: (1) Pengaturan lingkungan fisik mulai dari penataan lingkungan sekolah seperti memperbanyak taman dengan penghijauan, pembangunan gazebo dan kolam renang sampai dengan penataan ruang kelas seperti penataan tempat duduk dan pemberian hiasan kelas sehingga tercipta lingkungan yang nyaman, indah, dan kondusif; (2) Pengaturan suasana kerja yang dilakukan oleh kepala sekolah yaitu adanya program $3 \mathrm{~S}$ (Senyum, Salam, Sapa) dan program $5 \mathrm{H}, 5$ prinsip dalam pelayanan membangun suasana kerja, yang pertama yaitu happines, help, hope, healthy, humor; (3) Disiplin datang ke sekolah, disiplin mengikuti kegiatan sekolah, disiplin dalam hal meminta izin dan disiplin melaksanakan tugas; (4) Dorongan, kepala sekolah memberikan motivasi kepada guru seperti pemberian masukan dan teguran, nasihat atau bimbingan kepada guru, melakukan survei setiap pagi dan apel pagi. (5) Penghargaan yang diberikan kepala sekolah kepada guru yaitu seperti guru berprestasi, terdisiplin, terkreatif, tertertib administrasi, terfavorite, terprofesional, terupdate, dan tercomment; (6) Pengembangan pusat sumber belajar mulai dari pengadaan sarana dan prasarana, alat peraga serta menambah media pembelajaran sebagai penunjang belajar siswa. (7) Pembinaan rutin yang diadakan sepekan sekali setiap hari sabtu dengan materi atau tema yang berbeda setiap pekannya dan dari pembicara dibidangnya. Mulai dari dosen, psikolog dan lain sebagainya. (8) Mengadakan piknik atau rihlah bersama para guru. 


\section{DAFTAR PUSTAKA}

Abdulsalam, D., \& Mawoli, M.A. (2012). Motivation and job performance of academic staff of state universities in nigeria: The case of ibrahim badamasi babangida university, lapai, niger sate. International Journal Of Business And Management, 7 (14): 142-148.

Ali, S. N. M., Harun, C. Z., \& Djailani, A. R. (2015). Gaya kepemimpinan kepala sekolah dalam meningkatkan kinerja guru pada sd negeri lambaro angan. Jurnal Administrasi Pendidikan: Program Pascasarjana Unsyiah, 3(2):116-127.

Andari, S. (2013). Kontribusi manajemen supervise kepala sekolah, iklim organisasi, dan motivasi kerja terhadap guru SD di kecamatan wonosari, gunungkidul. Tesis. Tidak diterbitkan, Universitas Negeri Yogyakarta.

Busrin, D., Aunurrahman, A., \& Aswandi, A. (2014). Supervisi pengawas dan kemampuan manajerial kepala sekolah dengan kinerja guru smp negeri kota Pontianak. Disertasi. Universitas Tanjungpura.

Choir, Abu. (2013). Wajah baru manajemen pendidikan. Surakarta: IAIN Surakarta.

Departemen Pendidikan Nasional. (2005). Undang-undang nomor 14 tahun 2005, tentang guru dan dosen. Jakarta: Depdiknas.

Fanani, Z., Mardapi, D., \& Wuradji, W. (2014). Model asesmen kepemimpinan pembelajaran kepala sekolah pendidikan dasar. Jurnal Penelitian Dan Evaluasi Pendidikan, 18(1): 129145.

Fitrah, M. (2017). Peran kepala sekolah dalam meningkatkan mutu pendidikan. Jurnal Penjaminan Mutu, 3(1): 31-42.

Hardono, H., Haryono, H., \& Yusuf, A. (2017). Kepemimpinan kepala sekolah, supervisi akademik, dan motivasi kerja dalam meningkatkan kinerja guru. Educational Management, 6(1): 26- 33 .

Iskandar, U. (2013). Kepemimpinan kepala sekolah dalam peningkatan kinerja guru. Jurnal Visi Ilmu Pendidikan, 10(1): 1018-1027.

Karweti, E. (2010). Pengaruh kemampuan manajerial kepala sekolah dan faktor yang mempengaruhi motivasi kerja terhadap kinerja guru SLB di Kabupaten Subang. Jurnal Penelitian Pendidikan, 11(2): 77-89.

Moleong, Lexy. J. (2017). Metodologi pnenelitian kualitatif. Bandung: Remaja Rosdakarya.

Nurhayati, S. (2014). Membangun kepemimpinan yang efektif untuk meraih keunggulan kompetitif organisasi. Jurnal Eonomi Dan Bisnis, 15 (02): 21-27.

Pramesti, D., Muhyadi. (2018). Faktor-faktor yang mempenaruhi kinerja guru SMA. Harmoni Social Jurnal Pendidikan Ips, 5 (1): 43-56.

Prastowo, A. (2012). Metode penelitian kualitatif dalam perspektif rancangan penelitian. Jogjakarta: ArRuzz Media.

Rahmawati, U. (2016). Upaya kepala sekolah dalam meningkatkan kinerja guru di raudhatul athfal al khairiyah banjarsari kidul kecamatan sokaraja kabupaten banyumas tahun pelajaran 2015/2016. Thesis. IAIN Purwokerto.

Tukiyo. (2015). Motivasi dan kepuasan guru sekolah dasar di kabupaten klaten. Prosiding seminar nasional pendidikan. Universitas Sebelas Maret Surakarta. 